\title{
APPENDIX
}

\section{HIV Risk Assessment}




\section{HIV TESTING}

Who should get tested for HIV?

- Everyone between the ages of 13 and 64 should get tested for HIV at least once.

- If you are pregnant or planning to get pregnant, get tested as early as possible to protect yourself and your baby.

- You should get tested at least once a year if

- You are a sexually active gay or bisexual man. Some sexually active gay and bisexual men may benefit from more frequent testing (every 3 to 6 months).

Other people should get tested for HIV if you have

- Had sex with an HIV-positive partner.

- Had more than one partner since your last HIV test.

- Shared needles or works to inject drugs.

- Exchanged sex for drugs or money.

- Had another sexually transmitted infection, hepatitis, or tuberculosis.

- Had sex with anyone who has done anything listed earlier or with someone whose sexual history you do not know.

\section{HIV PREVENTION}

In addition to safer sex practices such as limiting partners and using condoms all the time, there are medications that help reduce the risk of HIV infection.

\section{POSTEXPOSURE PROPHYLAXIS}

Postexposure prophylaxis (PEP) involves taking medication after you may have been exposed to HIV to reduce your risk of getting HIV. If you may have been exposed to HIV in the last 72 hours, talk to your health care provider, an ED provider, or your local health department about PEP right away.

Who should consider PEP? In the last 72 hours were you

- Possibly exposed to HIV during sex-the condom broke or you did not use one

- Sharing needles and works to prepare drugs and inject drugs

- Sexually assaulted

How do I take PEP?

- PEP must be started within 72 hours (3 days) after you may have been exposed to HIV. But the sooner you start PEP, the better. Every hour counts!

- PEP needs to be taken once or twice daily for 28 days. Your provider will explain how to take the medication. It is very important that you take it as directed for the full 28 days. 
- PEP is effective in preventing HIV, but not $100 \%$. It should not be used routinely. You should always use condoms with sex partners and use clean needles and safe injection practices if you use drugs.

\section{PREEXPOSURE PROPHYLAXIS}

Preexposure Prophylaxis (PrEP) is for people who are HIV negative but at very high risk for HIV. PrEP involves taking medication every day to reduce the risk of getting HIV. PrEP can reduce your chance of getting HIV from sex by $90 \%$. If you inject drugs, PrEP can reduce your chance of HIV by $70 \%$. Using condoms all the time decreases your risk even more.

How to decide if PrEP is right for you?

If you are HIV negative and any of the following conditions apply to you:

\begin{tabular}{|c|c|c|}
\hline Gay or Bisexual Man & Heterosexual & Injection Drug User \\
\hline Have a HIV+ partner & Have a HIV+ partner & $\begin{array}{l}\text { Share needles or } \\
\text { equipment to inject } \\
\text { drugs }\end{array}$ \\
\hline $\begin{array}{l}\text { Have multiple } \\
\text { partners, a partner } \\
\text { with multiple } \\
\text { partners, or a partner } \\
\text { whose HIV status is } \\
\text { unknown, and you } \\
\text { also have anal sex } \\
\text { without a condom } \\
\text { or } \\
\text { Recently had a } \\
\text { sexually transmitted } \\
\text { infection }\end{array}$ & $\begin{array}{l}\text { Have multiple } \\
\text { partners, a partner } \\
\text { with multiple } \\
\text { partners, or a partner } \\
\text { whose HIV status is } \\
\text { unknown, and you } \\
\text { also do not always } \\
\text { use a condom for sex } \\
\text { with people who inject } \\
\text { drugs } \\
\text { or } \\
\text { Do not always use a } \\
\text { condom for sex with } \\
\text { bisexual men }\end{array}$ & $\begin{array}{l}\text { Are at risk for getting } \\
\text { HIV from sex }\end{array}$ \\
\hline
\end{tabular}

While taking PrEP, you need to have an HIV test every 3 months. If you do not have a health care provider and need help locating one who will prescribe PrEP, visit www.preplocator.org/

Source: Adapted from the Centers for Disease Control and Prevention (CDC): www.cdc.gov/hiv 